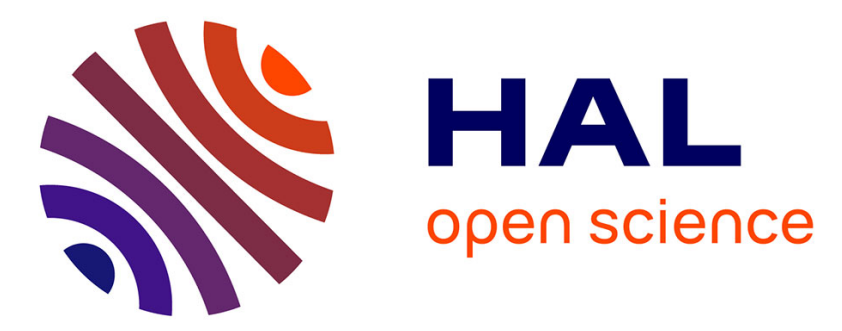

\title{
Psychosocial factors at work from the job strain model and preventable mortality in France: the STRESSJEM prospective study
}

Isabelle Niedhammer, Allison Milner, Béatrice Geoffroy-Perez, Thomas Coutrot, Anthony D Lamontagne, Jean-François Chastang

\section{To cite this version:}

Isabelle Niedhammer, Allison Milner, Béatrice Geoffroy-Perez, Thomas Coutrot, Anthony D Lamontagne, et al.. Psychosocial factors at work from the job strain model and preventable mortality in France: the STRESSJEM prospective study. Preventive Medicine, 2021, 153, pp.106178. 10.1016/j.ypmed.2020.106178 . hal-02863939

\section{HAL Id: hal-02863939 \\ https://univ-angers.hal.science/hal-02863939}

Submitted on 16 Jul 2020

HAL is a multi-disciplinary open access archive for the deposit and dissemination of scientific research documents, whether they are published or not. The documents may come from teaching and research institutions in France or abroad, or from public or private research centers.
L'archive ouverte pluridisciplinaire HAL, est destinée au dépôt et à la diffusion de documents scientifiques de niveau recherche, publiés ou non, émanant des établissements d'enseignement et de recherche français ou étrangers, des laboratoires publics ou privés. 
Psychosocial factors at work from the job strain model and preventable mortality in France: the STRESSJEM prospective study

Isabelle Niedhammer ${ }^{1}$, Allison Milner ${ }^{2}$, Béatrice Geoffroy-Perez ${ }^{3}$, Thomas Coutrot ${ }^{4}$, Anthony D. LaMontagne ${ }^{2,5}$, Jean-François Chastang ${ }^{1}$

1 INSERM, Univ Angers, Univ Rennes, EHESP, Irset (Institut de recherche en santé, environnement et travail) - UMR_S 1085, Epidemiology in Occupational Health and Ergonomics (ESTER) Team, Angers, France

${ }^{2}$ Centre for Health Equity, Melbourne School of Population and Global Health, University of Melbourne, Melbourne, Victoria 3010, Australia

${ }^{3}$ Santé publique France, Saint-Maurice, France

${ }^{4}$ DARES, Ministère du Travail, Paris, France

${ }^{5}$ Institute for Health Transformation \& School of Health \& Social Development, Deakin University, Geelong, Victoria 3125, Australia

\section{Correspondence to:}

Isabelle Niedhammer

INSERM U1085 - IRSET - Equipe ESTER

Faculté de Médecine - Université d'Angers

28 rue Roger Amsler

CS 74521

49045 ANGERS Cedex 01

France

Email: isabelle.niedhammer@inserm.fr

Word count of abstract: 249

Word count of text: 3488

Number of references: 25

Number of tables: 3

Supplementary Material

We wish to dedicate this paper to the memory of our highly valued colleague, Allison Milner, who died tragically and prematurely in August 2019. 


\begin{abstract}
The study aimed to explore the prospective associations between psychosocial factors at work from the job strain model and preventable mortality, including smoking- and alcohol-related mortality as well as external causes of death. The study was based on prospective data and relied on a sample of 1,511,456 individuals for which data on job history, mortality and causes of death were linked over the 1976-2002 period. Exposures were the factors from the job strain model imputed through a job-exposure matrix. Various time-varying measures of exposure were used including current exposure and two measures of cumulative exposure. Preventable mortality was defined using the OECD/Eurostat list of preventable causes of death. The associations between exposures and outcomes were studied using Cox proportional hazards models. Effect modification by gender was also assessed. Over the study period, 57,264 preventable deaths occurred before the age of 75 years. Low decision latitude, low social support, job strain, iso-strain, passive job, and high strain were associated with preventable mortality, and associations of stronger magnitude were found for job strain and iso-strain among men. Stronger associations were observed for alcohol-related mortality than for smoking-related mortality and external causes of death. The fractions of preventable mortality attributable to current exposure to job strain and iso-strain were significant among men only (5.1\% and 3.3\%). Psychosocial factors at work from the job strain model may play a role on preventable mortality. Intensifying research and prevention towards the psychosocial work environment may be helpful to reduce risky health-related behaviours and related mortality.
\end{abstract}

Key words: preventable mortality; smoking-related mortality; alcohol-related mortality; external causes of death; job stress; psychosocial work factors; cumulative exposure 


\section{Introduction}

Psychosocial work exposures are an important topic in the area of occupational health among working populations in developed countries. These exposures have often been measured through a well-recognized theoretical model, the job strain model by Karasek (Karasek et al., 1998). This model includes three main factors, decision latitude (including both skill discretion and decision authority), psychological demands (including various aspects of demands at work such as excessive amount of work, intense concentration, interruptions, time pressure, conflicting demands, etc.), and social support from both superiors and colleagues, as well as the combined factors of job strain (combining high demands and low latitude) and isostrain (combining job strain and low support). Indeed, the combination of factors are expected to be particularly harmful to health outcomes. In the literature, the study of these factors often relies on one measured time point of exposure only, performed at baseline (i.e. at the beginning of follow-up) in prospective studies. Consequently, repeated long-term measures as well as cumulative measures of exposure are often lacking in the literature.

These psychosocial work factors have been found to be associated with various morbidity outcomes, mainly mental disorders (Madsen et al., 2017; Theorell et al., 2015) and cardiovascular diseases (Kivimaki et al., 2012; Xu et al., 2015). To get a better understanding of the effects of these factors on health, studies have also been carried out on the associations of these factors with health-related behaviours such as smoking, alcohol intake, or physical inactivity. Recent reviews and/or meta-analyses (Fransson et al., 2012; Heikkila et al., 2013a; Heikkila et al., 2012a, b; Nyberg et al., 2013) provided some evidence for these associations that may contribute to an increased risk of morbidity outcomes such as cardiovascular diseases. Furthermore, as these behaviours may also have adverse effects on other health outcomes such as cancers, digestive and respiratory diseases, injuries and accidents, the study of the associations between psychosocial work factors and health behaviours may be informative and useful to better understand the health effects of these factors.

There are, however, few studies on the associations of psychosocial work factors with morbidity related to health behaviours, and studies are totally lacking with mortality related to health behaviours. In this context, the concept of preventable mortality is particularly pertinent as psychosocial factors at work may be subject to primary prevention policies. According to OECD/Eurostat (OECD/Eurostat, 2019), preventable mortality is defined as 
follows: "Causes of death that can be mainly avoided through effective public health and primary prevention interventions (i.e. before the onset of diseases/injuries, to reduce incidence)" (page 4). These causes of death are strongly related to health behaviours, most importantly smoking, alcohol use, physical inactivity, and nutrition, but also more widely to high-risk behaviours involved in external causes of death (accidents and injuries). As there is little literature on the effects of psychosocial work factors on preventable mortality, studies examining the effects of these factors on total preventable mortality and leading subtypes of this mortality are particularly useful.

The study hypotheses were the following. As most previous prospective studies in the field of psychosocial factors at work used exposure measure at baseline only, we expected repeated measures of exposure over time to be more powerful predictors of the health effects of these factors. Furthermore, as dose-response associations may be important in the understanding of the etiological role of these factors, cumulative measures of exposure over time will be studied. Given the effects of psychosocial work factors on health behaviours (namely smoking, alcohol use, physical inactivity, etc.) already observed in the literature, these factors were expected to predict preventable mortality, including subtypes of this mortality.

The objectives of this study were thus to examine the associations between various exposure measures for psychosocial factors at work from the job strain model and preventable mortality in a large national representative sample of the working population. An additional objective was to provide information on smoking- and alcohol-related mortality as well as external causes of death specifically.

\section{Methods}

The details of the protocol and methods of the STRESSJEM study can be found in a previous publication (Niedhammer et al., 2019).

\section{Study sample}

Briefly, the study sample was a nationally representative prospective cohort that used both the data of the national SUMER survey (DARES of the French Ministry of Labour) and of the COSMOP program (Santé publique France). Both the SUMER survey and the COSMOP program were based on national representative data of the general working population of 
employees and excluded some rare groups of workers: self-employed workers, agricultural workers/employees, employees of some public sectors and of household activities and extraterritorial organisations. Consequently, the target population and data were comparable for the two sources of data. For the study sample, i.e. 1,511,456 individuals, data on job history from 1976 to 2002 (INSEE DADS Panel data, a random sample -1/24th- of the French national working population of employees) were linked to mortality data and causes of death coded using the ICD over the period 1976-2005 using personal identifiers (French national death registry, INSERM-CépiDc). Data included the following information about job history, for all jobs held, over the period 1976-2002: dates of start and end of job, occupation, economic activity of the company, and company size. A job-exposure matrix (JEM) was constructed using the data of the SUMER survey to provide estimates of exposure for the recommended job strain model questionnaire (JCQ) according to three job title variables (occupation, economic activity and company size). To study the validity of this JEM, we compared individual exposures and JEM-derived measures of exposure and studied the associations with self-reported health (Niedhammer et al., 2018). In the COSMOP program, there was no exposure assessment for the job strain model, but there were data for the same three job title variables, that were used to impute exposure estimates from the JEM for each job held during the 1976-2002 period.

\section{Outcomes}

Preventable mortality was defined using the full OECD/Eurostat list of preventable causes of death (OECD/Eurostat, 2019). This list includes a large number of death causes related to infectious diseases, cancer, diseases of the circulatory and respiratory system, injuries, alcohol and drug related disorders, etc. Three additional outcomes, that were subgroups of the full list of preventable mortality, were also studied: smoking- and alcohol-related mortality, and external causes of death. Alcohol-related mortality and external causes of death were defined on the basis of the OECD/Eurostat list, and smoking-related mortality by all causes of death that were identified in the OECD/Eurostat list as prevented through smoking prevention measures. In accordance with OECD/Eurostat list, as preventable mortality focusses on premature deaths, the age threshold of under 75 years was used.

\section{Measures of exposure}

Using all jobs held within the 1976-2002 period, three time-varying measures of exposure were calculated on a daily basis (i being any day within the study period): 
1) Current exposure at time i provided current exposure on a given day $\mathrm{i}$.

2) Cumulative exposure until time $i$ was a time-weighted average measure at time $i$ combining both exposure estimates and time spent in all jobs up to and including time $\mathrm{i}$ (i.e. an average measure of all (past and current) exposures until time i).

3) Recency-weighted cumulative exposure at time i was a weighted average measure at time i combining both exposure estimates within the 5 past years and time elapsed since exposure with higher weights assigned to more recent exposures (i.e. a recency-weighted average measure of all exposures within the 5 past years and until time i). We made the assumption that psychosocial work exposure effects persisted for a period of up to 5 years after the end of exposure (Amick et al., 2002) and thus decreased linearly over a 5-year period to be null after 5 years.

The measures used for current exposure were:

-psychological demands, decision latitude, and social support, as binary variables, derived from the JEM scores dichotomized at the median of the distribution for the first job among the total sample of men and women

-the binary variables for job strain and isostrain, calculated from the binary variables of demands, latitude, and support

-the 4-category variable defining the four quadrants by Karasek, from the combination of demands and latitude, i.e. high strain (high demands and low latitude), low strain (low demands and high latitude), passive job (low demands and low latitude), and active job (high demands and high latitude), the reference group.

The measures used for the two cumulative exposures (cumulative exposure and recencyweighted cumulative exposure) were based on time-weighted scores for demands, latitude, and support as previously defined and dichotomized. Job strain, isostrain, and the 4-quadrant variable were constructed as mentioned earlier.

\section{Statistical methods}

The hazard ratio (HR) of preventable mortality was estimated according to the studied exposures using Cox proportional hazards models. The studied exposures were timedependent variables. Age was used as the time scale. Calendar time and four occupational variables related to biomechanical, physical, chemical and biological exposures were included as adjustment variables. These four exposures were assessed by occupational physicians using 
national and European standards in the SUMER survey (Niedhammer et al., 2008a) and were used to cover all types of occupational exposures that were not related to the psychosocial work environment. They were imputed though a JEM using the same methodology as psychosocial work factors (Niedhammer et al., 2018). These exposures were used as proxies for socioeconomic status, these exposures being strongly associated with social position (Niedhammer et al., 2008b). We used a model with delayed entry. Individuals entered the cohort on the $1^{\text {st }}$ January 1976 if they already had a job or when they started a first job within the 1976-2002 period.

Death for other causes than preventable mortality were censored at that time.

For the 3 exposure measures, we used preventable mortality until the end of last job, to study preventable mortality during time intervals with a job (called 'on-the-job' preventable mortality); thus in this analysis, the follow-up ended at the time of death or at the end date of the last job within the 1976-2002 period, or at the end of follow-up (31th December 2002) if still working at this time, whichever came first. The age threshold of under 75 years was used but there was no one working over 75 years in our study sample.

For the 2 measures of cumulative exposure, as delayed effects may be expected, a second analysis was performed in which the follow-up ended at the time of death or on the 31th December 2002 or at the age of 75 years, whichever came first.

Three types of models were performed: (1) including each exposure separately, (2) including the exposures of demands, latitude, and support simultaneousy, (3) including job strain, isostrain, and the 4-quadrant variable respectively.

Comparisons between the three models using the three exposure measures (current, cumulative, and recency-weighted cumulative exposure) in association with on-the-job preventable mortality were performed to identify the model with the best relative quality using Akaike's Information Criterion (AIC).

All analyses were performed separately for men and women and using SAS and R. Interaction terms were also tested between gender and psychosocial work exposures in the total sample to explore potential gender-related differences in the exposure-outcome associations. 


\section{Sensitivity analyses}

Sensitivity analyses were performed to test the robustness of the results:

-using exposure scores instead of binary variables

-adjusting for occupation instead of adjusting for the four biomechanical, physical, chemical and biological exposures

-imputing the lowest level of exposure instead of the highest level of exposure in case of multiple job-holder (only $3 \%$ of the sample had more than one job at the same time) -studying mortality until 2005 instead of 2002

\section{Results}

Among the initial sample, 1,496,332 individuals, including 798,547 men and 697,785 women, had no missing values for job history. Within the 1976-2002 period, 45,730 preventable deaths occurred among men and 8,996 occurred among women, including 11,534 preventable deaths among men and 1,931 among women during time intervals with a job (i.e. 21-25\% of deaths occurred as 'on-the-job' preventable mortality). The number of deaths for smokingand alcohol-related mortality and external causes of death are presented in Supplementary Tables S1-S9. Preventable mortality represented 46.6\% (51.7\% among men, 31.1\% among women) of total mortality in our sample over the study period. The proportions were the following for smoking-related mortality, $25.6 \%$ (29.7\% for men, $13.1 \%$ for women), alcoholrelated mortality, $5.4 \%$ (5.7\% for men, $4.3 \%$ for women), and external causes of death, $12.7 \%$ (13.5\% for men, $10.5 \%$ for women). A description of psychosocial work exposures among the study sample is presented in our study protocol (Niedhammer et al., 2019).

Tables 1-3 provide the results of the associations between psychosocial work exposures and preventable mortality using current exposure (Table 1), cumulative exposure (Table 2) and recency-weighted cumulative exposure (Table 3). Low decision latitude and low social support were found to be associated with preventable mortality in all models when these exposures were studied separately. Low decision latitude was also found to be a risk factor in almost all models when it was studied with the other factors. Job strain and iso-strain were risk factors for preventable mortality among men and also among women when cumulative or recency-weighted cumulative exposure were studied in association with preventable mortality during time intervals with a job (on-the-job preventable mortality). High strain was a risk 
factor in all models. Passive job was also observed as a risk factor except among women when cumulative exposures and on-the-job preventable mortality were studied. Psychological demands was either non-significant or a protective factor. There was however an exception, the cumulative exposure (Tables 2-3) was a risk factor for on-the-job preventable mortality among women. Low strain was a risk factor among men whereas among women, this exposure had a protective effect on on-the-job preventable mortality, suggesting a difference in the low-risk work situation that was active job for men and low strain for women. The sensitivity analyses provided similar results, except the sensitivity analysis adjusted for occupation, that led to slightly lower exposure-outcome associations, which was expected as this adjustment was considered as an overadjustment, as psychosocial work factors were derived from a JEM using occupation among the job title variables.

Supplementary Tables S1-9 show the results for smoking- and alcohol-related mortality and external causes of death. Although these results were based on a lower number of cases of mortality especially among women, similar patterns were observed for these causes of death compared to total preventable mortality. The results for alcohol-related mortality displayed stronger exposure-outcome associations than the results for the two other outcomes.

Significant gender-related interaction terms were observed in the exposure-outcome associations. No clear pattern in gender differences was identified, except the stronger associations of job strain and iso-strain with preventable mortality among men compared to women.

The model using current exposure had the lowest AIC value (i.e. the best relative quality), but without significant differences with the two other models with cumulative and recencyweighted cumulative exposure. This is why we calculated the attributable fractions for current exposure. The fractions of preventable mortality attributable to job strain were $5.1 \%$ (95\% CI: 3.8-6.5) for men and 3.1\% (95\% CI: 0-6.6) for women, and those attributable to iso-strain were $3.3 \%$ (95\% CI: 2.3-4.3) for men and 1.9\% (95\% CI: 0-4.3) for women. Consequently, the AFs were significant for men only. However, the AFs might be underestimated among women, as we used HRs from Table 1 which were not significant, whereas HRs in association with on-the-job preventable mortality were significant in Tables 2-3.

\section{Discussion}




\section{Summary of the results}

Our study underlined that psychosocial work exposures of the job strain model were associated with preventable mortality. These exposures were low decision latitude, low social support, job strain, iso-strain, passive job, and high strain. On examination of major subgroups of preventable mortality, stronger associations were found for alcohol-related mortality than for smoking-related mortality and external causes of death. Differences in the exposure-outcome associations were observed between genders. The fractions of preventable mortality attributable to job strain and iso-strain were significant among men $(5.1 \%$ and $3.3 \%$ respectively for job strain and iso-strain).

\section{Comparison with the literature}

Our study is the first to explore the associations between psychosocial work exposures of the job strain model and preventable mortality, consequently there are no direct comparisons possible with the published literature. Previous reviews/meta-analyses examined the associations of job strain with morbidity outcomes that may contribute at least partly to preventable mortality: cardiovascular diseases especially coronary heart diseases (Kivimaki and Kawachi, 2015) and stroke (Fransson et al., 2015), cancer (Heikkila et al., 2013b; Yang et al., 2019), digestive (Heikkila et al., 2014a) and respiratory diseases (Heikkila et al., 2014b; Heikkila et al., 2014c). Among these morbidity outcomes, convincing evidence has been provided for cardiovascular diseases only. Some reviews/meta-analyses explored the associations of job strain and health-related behaviours. The results were found to be significant between job strain and smoking (Heikkila et al., 2012b; Nyberg et al., 2013) and alcohol use (Heikkila et al., 2012a; Nyberg et al., 2013), although these results were more frequently significant for cross-sectional than prospective studies. In addition, the effects of job strain on smoking and alcohol use were of similar magnitude in the literature, whereas we found stronger associations of psychosocial work factors with alcohol-related mortality than with smoking-related mortality and external causes of death. Job strain, high strain, and passive job were found to increase the risk of physical inactivity (Fransson et al., 2012; Nyberg et al., 2013). Job strain was associated with obesity in cross-sectional studies but was not significant in prospective studies (Kivimaki et al., 2015; Nyberg et al., 2013; Nyberg et al., 2012). Job strain was also associated with increased risk of unhealthy lifestyles (Heikkila et al., 2013a). Thus, the literature on cardiovascular diseases and health-related behaviours 
supports the plausibility of the associations between psychosocial work exposures of the job strain model and preventable mortality.

Our results would probably need confirmation on two points.

Most previous prospective studies exploring the health effects of psychosocial factors at work used a measure of exposure at baseline, which may lead to misclassification of exposure, related to changes in exposure, especially if the time between exposure and outcome is long. In our study, as we had a complete follow-up of exposure, we were able to construct a measure of current exposure, based on repeated measures over time, which was useful to take all changes in exposure into account. This exposure appears more adequate to capture the effects of psychosocial factors at work over time compared to exposure measure at baseline. We found that the models with current exposure had a higher relative quality than those with cumulative measures of exposure, though not significant. The results were very close for the three exposure measures, and the absence of significance between the models did not allow us to make a definite conclusion on the best exposure measure. A confirmation is thus needed on whether or not current or recent exposure is really more pertinent than cumulative or past exposure in association with preventable mortality.

Psychosocial factors at work were found to have predictive effects on preventable mortality, including three subtypes of this mortality. Their effects were particularly strong for alcoholrelated mortality. This finding which may be important from a public health perspective may need further exploration, as such differences in the magnitude of the effects were not found in the study of smoking- and alcohol-related behaviours previously.

\section{Limitations and strengths of the study}

The strengths of the study included: very large national representative sample, prospective data, study of both men and women and of gender differences, long follow-up for both exposure and outcome, no response, participation or selection bias (a healthy worker effect is however likely for the study of current exposure and on-the-job preventable mortality), no attrition bias, no reporting bias for both exposure (JEM) and outcome, use of the validated and recommended questionnaire for the job strain model (JCQ), study of different measures of time-varying exposure, and mortality provided by the French national death registry. Several sensitivity analyses were performed that confirmed the robustness of the results. Finally, to 
our knowledge, this study is the first to explore the associations between psychosocial work factors and preventable mortality.

A number of limitations should, however, be acknowledged: limited number of adjustment/stratification variables (in particular to control for socioeconomic status directly), the potential for residual confounding, the inherent limitations of job-exposure matrix, leading to a bias towards the null hypothesis, missing information for some jobs, that was treated using midcensoring, and no evaluation of complete working life course measures of exposure. As these limitations included both under- and over-estimation effects, it was however difficult to conclude on the net impact on the results.

\section{Conclusion}

Psychosocial exposures at work from the job strain model were associated with preventable mortality, and specific preventable causes of death. Preventable mortality represents a high proportion of total mortality. More research and preventive interventions to improve the psychosocial work environment may be beneficial for the prevention of unhealthy behaviours, and of morbidity and mortality related to these behaviours. 


\section{Acknowledgements}

The authors thank the members of the DARES (French ministry of labour), all the occupational physicians and 'médecins inspecteurs régionaux du travail', and all the employees who participated to the SUMER survey. The authors thank Catherine Buisson, Laurence Chérié-Challine and Pascal Empereur-Bissonnet at Santé publique France (Direction Sante Travail) for the access to the COSMOP data. The authors also thank all people and public institutions who contributed directly or indirectly to the final COSMOP database, especially INSEE and INSERM-CépiDc.

\section{Funding}

This study was supported by the French National Research Program for Environmental and Occupational Health of ANSES, France (grant number: EST-2016/1/49). The funder had no role in study design; in the collection, analysis and interpretation of data; in the writing of the report; and in the decision to submit the article for publication.

\section{Author contributions}

IN is the principal investigator who designed the project and drafted and revised the manuscript. JFC and AM made substantial contributions to the design of the project. JFC, AM and $\mathrm{AL}$ were involved in revising the manuscript critically for important scientific content. JFC was in charge of all statistical analyses. BGP is in charge of the COSMOP dataset at Santé publique France and TC is in charge of the SUMER dataset at DARES; they both provided technical help on these datasets. All authors have read, reviewed and approved the final version of the manuscript.

\section{Ethics approval}

Ethical permissions were granted by French ethics committees: Commission Nationale de l'Informatique et des Libertés (no 762430V1 and no 04-1274) and Conseil National de l'Information Statistique (no 2009X705TV).

\section{Conflicts of interest}

None 


\section{References}

Amick, B.C., III, McDonough, P., Chang, H., Rogers, W.H., Pieper, C.F., Duncan, G., 2002. Relationship between all-cause mortality and cumulative working life course psychosocial and physical exposures in the United States labor market from 1968 to 1992. Psychosom. Med 64:370-81.

Fransson, E.I., Heikkila, K., Nyberg, S.T., Zins, M., Westerlund, H., Westerholm, P., Vaananen, A., Virtanen, M., Vahtera, J., et al., 2012. Job strain as a risk factor for leisuretime physical inactivity: an individual-participant meta-analysis of up to 170,000 men and women: the IPD-Work Consortium. Am J Epidemiol 176:1078-89.

Fransson, E.I., Nyberg, S.T., Heikkila, K., Alfredsson, L., Bjorner, J.B., Borritz, M., Burr, H., Dragano, N., Geuskens, G.A., et al., 2015. Job strain and the risk of stroke: an individualparticipant data meta-analysis. Stroke 46:557-59.

Heikkila, K., Fransson, E.I., Nyberg, S.T., Zins, M., Westerlund, H., Westerholm, P., Virtanen, M., Vahtera, J., Suominen, S., et al., 2013a. Job strain and health-related lifestyle: findings from an individual-participant meta-analysis of 118,000 working adults. Am J Public Health 103:2090-7.

Heikkila, K., Madsen, I.E., Nyberg, S.T., Fransson, E.I., Ahola, K., Alfredsson, L., Bjorner, J.B., Borritz, M., Burr, H., et al., 2014a. Job strain and the risk of inflammatory bowel diseases: individual-participant meta-analysis of 95,000 men and women. PLoS One 9:e88711.

Heikkila, K., Madsen, I.E., Nyberg, S.T., Fransson, E.I., Ahola, K., Alfredsson, L., Bjorner, J.B., Borritz, M., Burr, H., et al., 2014b. Job strain and COPD exacerbations: an individual-participant meta-analysis. Eur Respir J 44:247-51.

Heikkila, K., Madsen, I.E., Nyberg, S.T., Fransson, E.I., Westerlund, H., Westerholm, P.J., Virtanen, M., Vahtera, J., Vaananen, A., et al., 2014c. Job strain and the risk of severe asthma exacerbations: a meta-analysis of individual-participant data from 100000 European men and women. Allergy 69:775-83.

Heikkila, K., Nyberg, S.T., Fransson, E.I., Alfredsson, L., De Bacquer, D., Bjorner, J.B., Bonenfant, S., Borritz, M., Burr, H., et al., 2012a. Job strain and alcohol intake: a collaborative meta-analysis of individual-participant data from 140,000 men and women. PLoS One 7:e40101.

Heikkila, K., Nyberg, S.T., Fransson, E.I., Alfredsson, L., De Bacquer, D., Bjorner, J.B., Bonenfant, S., Borritz, M., Burr, H., et al., 2012b. Job strain and tobacco smoking: an individual-participant data meta-analysis of 166,130 adults in 15 European studies. PLoS One 7:e35463.

Heikkila, K., Nyberg, S.T., Theorell, T., Fransson, E.I., Alfredsson, L., Bjorner, J.B., Bonenfant, S., Borritz, M., Bouillon, K., et al., 2013b. Work stress and risk of cancer: meta-analysis of 5700 incident cancer events in 116,000 European men and women. BMJ 346:f165.

Karasek, R., Brisson, C., Kawakami, N., Houtman, I., Bongers, P., Amick, B., 1998. The Job Content Questionnaire (JCQ): an instrument for internationally comparative assessments of psychosocial job characteristics. J. Occup. Health Psychol 3:322-55.

Kivimaki, M., Kawachi, I., 2015. Work Stress as a Risk Factor for Cardiovascular Disease. Curr Cardiol Rep 17:630.

Kivimaki, M., Nyberg, S.T., Batty, G.D., Fransson, E.I., Heikkila, K., Alfredsson, L., Bjorner, J.B., Borritz, M., Burr, H., et al., 2012. Job strain as a risk factor for coronary heart disease: a collaborative meta-analysis of individual participant data. Lancet 380:1491-97. 
Kivimaki, M., Singh-Manoux, A., Nyberg, S., Jokela, M., Virtanen, M., 2015. Job strain and risk of obesity: systematic review and meta-analysis of cohort studies. Int J Obes (Lond) 39:1597-600.

Madsen, I.E.H., Nyberg, S.T., Magnusson Hanson, L.L., Ferrie, J.E., Ahola, K., Alfredsson, L., Batty, G.D., Bjorner, J.B., Borritz, M., et al., 2017. Job strain as a risk factor for clinical depression: systematic review and meta-analysis with additional individual participant data. Psychol Med 47:1342-56.

Niedhammer, I., Chastang, J.F., David, S., 2008a. Importance of psychosocial work factors on general health outcomes in the national French SUMER survey. Occup. Med. (Lond) 58:15-24.

Niedhammer, I., Chastang, J.F., David, S., Kelleher, C., 2008b. The contribution of occupational factors to social inequalities in health: findings from the national French SUMER survey. Soc. Sci. Med 67:1870-81.

Niedhammer, I., Milner, A., Geoffroy-Perez, B., Coutrot, T., LaMontagne, A.D., Chastang, J.F., 2019. Prospective associations of psychosocial work exposures with mortality in France: STRESSJEM study protocol. BMJ Open 9:e031352. doi:10.1136/bmjopen-2019031352.

Niedhammer, I., Milner, A., LaMontagne, A.D., Chastang, J.F., 2018. Study of the validity of a job-exposure matrix for the job strain model factors: an update and a study of changes over time. Int Arch Occup Environ Health 91:523-36.

Nyberg, S.T., Fransson, E.I., Heikkila, K., Alfredsson, L., Casini, A., Clays, E., De Bacquer, D., Dragano, N., Erbel, R., et al., 2013. Job strain and cardiovascular disease risk factors: meta-analysis of individual-participant data from 47,000 men and women. PLoS One 8:e67323.

Nyberg, S.T., Heikkila, K., Fransson, E.I., Alfredsson, L., De, B.D., Bjorner, J.B., Bonenfant, S., Borritz, M., Burr, H., et al., 2012. Job strain in relation to body mass index: pooled analysis of 160000 adults from 13 cohort studies. J. Intern. Med 272:65-73.

OECD/Eurostat, 2019. Avoidable mortality: OECD/Eurostat lists of preventable and treatable causes of death (2019 version), Organisation for Economic Co-operation and Development \& EUROPEAN COMMISSION, EUROSTAT, Directorate F: Social statistics, Unit F-5: Education, health and social protection.

Theorell, T., Hammarstrom, A., Aronsson, G., Traskman Bendz, L., Grape, T., Hogstedt, C., Marteinsdottir, I., Skoog, I., Hall, C., 2015. A systematic review including meta-analysis of work environment and depressive symptoms. BMC Public Health 15:738.

Xu, S., Huang, Y., Xiao, J., Zhu, W., Wang, L., Tang, H., Hu, Y., Liu, T., 2015. The association between job strain and coronary heart disease: a meta-analysis of prospective cohort studies. Ann Med 47:512-8.

Yang, T., Qiao, Y., Xiang, S., Li, W., Gan, Y., Chen, Y., 2019. Work stress and the risk of cancer: A meta-analysis of observational studies. Int J Cancer 144:2390-400. 
Table 1. Associations between current exposure and preventable mortality among men and women

\begin{tabular}{lcc}
\hline & MEN (N=798,547) & WOMEN (N=697,785) \\
\hline & $\begin{array}{c}\text { HR (95\% CI) } \\
\text { (Deaths=11,534) }\end{array}$ & $\begin{array}{c}\text { HR (95\% CI) } \\
\text { (Deaths=1,931) }\end{array}$ \\
\hline High psychological demands $^{\mathrm{a}}$ & $0.88[0.84-0.93]$ & $1.05[0.95-1.17]$ \\
\hline Low decision latitude $^{\mathrm{a}}$ & $1.33[1.27-1.38]$ & $1.33[1.17-1.51]$ \\
\hline Low social support $^{\mathrm{a}}$ & $1.28[1.23-1.34]$ & $1.22[1.10-1.35]$ \\
\hline High psychological demands $^{\mathrm{b}}$ & $0.98[0.93-1.03]$ & $1.07[0.96-1.19]$ \\
Low decision latitude $^{\mathrm{b}}$ & $1.26[1.18-1.34]$ & $1.26[1.08-1.48]$ \\
Low social support $^{\mathrm{b}}$ & $1.06[0.99-1.14]$ & $1.09[0.97-1.24]$ \\
\hline Job strain $^{\mathrm{a}}$ & $1.27[1.20-1.35]$ & $1.11[0.98-1.25]$ \\
\hline Isostrain $^{\mathrm{a}}$ & $1.27[1.19-1.35]$ & $1.11[0.99-1.26]$ \\
\hline Quadrants by Karasek & \\
Active job (ref) & 1 & 1 \\
Low strain $_{\text {Passive job }}^{\mathrm{a}}$ & $1.11[1.04-1.18]$ & $0.74[0.62-0.89]$ \\
High strain & $1.37[1.29-1.45]$ & $1.24[1.06-1.44]$ \\
\hline a Each exposure was studied sepate & $1.20[1.03-1.40]$
\end{tabular}

${ }^{\mathrm{a}}$ Each exposure was studied separately

${ }^{\mathrm{b}}$ Demands, latitude and support were studied simultaneously

High strain (high demands and low latitude), low strain (low demands and high latitude), passive job (low demands and low latitude), and active job, the reference group (high demands and high latitude)

All models were adjusted for calendar time, biomechanical, physical, chemical and biological exposures 
Table 2. Associations between cumulative exposure and preventable mortality among men and women

\begin{tabular}{|c|c|c|c|c|}
\hline & $\begin{array}{c}\text { MEN } \\
(\mathrm{N}=798,547)\end{array}$ & & $\begin{array}{c}\text { WOMEN } \\
(\mathrm{N}=697,785)\end{array}$ & \\
\hline \multirow[t]{2}{*}{ Follow-up } & On-the-job & $\begin{array}{c}\text { Follow-up until } \\
\text { 31/12/2002 }\end{array}$ & On-the-job & $\begin{array}{c}\text { Follow-up until } \\
31 / 12 / 2002\end{array}$ \\
\hline & $\begin{array}{c}\text { HR }(95 \% \text { CI }) \\
(\text { Deaths }=11 \text { 534) }\end{array}$ & $\begin{array}{c}\text { HR }(95 \% \text { CI }) \\
(\text { Deaths }=45730)\end{array}$ & $\begin{array}{c}\text { HR }(95 \% \text { CI }) \\
(\text { Deaths=1 931) }\end{array}$ & $\begin{array}{c}\text { HR }(95 \% \text { CI }) \\
\text { (Deaths=8 996) }\end{array}$ \\
\hline High psychological demands $^{a}$ & $0.91[0.87-0.96]$ & $0.85[0.83-0.87]$ & $1.18[1.06-1.32]$ & $0.87[0.83-0.91]$ \\
\hline Low decision latitude $^{\mathrm{a}}$ & $1.31[1.26-1.36]$ & $1.24[1.21-1.26]$ & $1.18[1.06-1.32]$ & $1.30[1.23-1.38]$ \\
\hline Low social support ${ }^{\mathrm{a}}$ & $1.25[1.20-1.31]$ & $1.08[1.06-1.11]$ & $1.30[1.17-1.44]$ & $1.13[1.07-1.18]$ \\
\hline High psychological demands ${ }^{b}$ & $0.97[0.92-1.02]$ & $0.89[0.87-0.92]$ & $1.16[1.03-1.30]$ & $0.87[0.83-0.92]$ \\
\hline Low decision latitude $\mathrm{e}^{\mathrm{b}}$ & $1.22[1.17-1.28]$ & $1.22[1.19-1.25]$ & $1.12[0.98-1.27]$ & $1.23[1.16-1.31]$ \\
\hline Low social support ${ }^{\mathrm{b}}$ & $1.15[1.09-1.20]$ & $0.98[0.96-1.01]$ & $1.21[1.08-1.37]$ & $1.09[1.03-1.15]$ \\
\hline Job strain $^{\mathrm{a}}$ & $1.23[1.16-1.31]$ & $1.20[1.16-1.24]$ & $1.19[1.07-1.32]$ & $1.00[0.95-1.05]$ \\
\hline Isostrain $^{\mathrm{a}}$ & $1.25[1.18-1.34]$ & $1.17[1.13-1.21]$ & $1.20[1.08-1.33]$ & $1.00[0.95-1.05]$ \\
\hline \multicolumn{5}{|l|}{ Quadrants by Karasek $^{\mathrm{a}}$} \\
\hline Active job (ref) & 1 & 1 & 1 & 1 \\
\hline Low strain & $1.05[0.99-1.12]$ & $1.21[1.17-1.25]$ & $0.67[0.54-0.84]$ & $0.96[0.87-1.05]$ \\
\hline Passive job & $1.34[1.26-1.42]$ & $1.37[1.33-1.41]$ & $1.01[0.87-1.17]$ & $1.42[1.33-1.52]$ \\
\hline High strain & $1.36[1.27-1.46]$ & $1.38[1.33-1.43]$ & $1.15[1.01-1.31]$ & $1.20[1.13-1.28]$ \\
\hline
\end{tabular}

${ }^{a}$ Each exposure was studied separately

${ }^{\mathrm{b}}$ Demands, latitude and support were studied simultaneously

High strain (high demands and low latitude), low strain (low demands and high latitude), passive job (low demands and low latitude), and active job, the reference group (high demands and high latitude)

All models were adjusted for calendar time, biomechanical, physical, chemical and biological exposures 
Table 3. Associations between recency-weighted cumulative exposure and preventable mortality among men and women

\begin{tabular}{|c|c|c|c|c|}
\hline & $\begin{array}{c}\text { MEN } \\
(\mathrm{N}=798,547)\end{array}$ & & $\begin{array}{c}\text { WOMEN } \\
(\mathrm{N}=697,785)\end{array}$ & \\
\hline \multirow[t]{2}{*}{ Follow-up } & On-the-job & $\begin{array}{c}\text { Follow-up until } \\
\text { 31/12/2002 }\end{array}$ & On-the-job & $\begin{array}{c}\text { Follow-up until } \\
\text { 31/12/2002 }\end{array}$ \\
\hline & $\begin{array}{c}\text { HR }(95 \% \text { CI }) \\
(\text { Deaths }=11534)\end{array}$ & $\begin{array}{c}\text { HR }(95 \% \text { CI }) \\
(\text { Deaths }=45730)\end{array}$ & $\begin{array}{c}\text { HR }(95 \% \text { CI }) \\
(\text { Deaths }=1931)\end{array}$ & $\begin{array}{c}\text { HR }(95 \% \text { CI }) \\
\text { (Deaths=8 996) }\end{array}$ \\
\hline High psychological demands $^{\mathrm{a}}$ & $0.90[0.85-0.94]$ & $0.81[0.79-0.84]$ & $1.21[1.09-1.35]$ & $0.84[0.79-0.90]$ \\
\hline Low decision latitude $^{\mathrm{a}}$ & $1.35[1.29-1.41]$ & $1.22[1.19-1.25]$ & $1.30[1.16-1.47]$ & $1.39[1.29-1.50]$ \\
\hline Low social support $^{\mathrm{a}}$ & $1.39[1.33-1.45]$ & $1.15[1.12-1.18]$ & $1.33[1.20-1.47]$ & 1.12 [1.05-1.19] \\
\hline High psychological demands $^{b}$ & 0.99 [0.94-1.04] & $0.85[0.82-0.88]$ & $1.21[1.08-1.36]$ & 0.87 [0.81-0.93] \\
\hline Low decision latitude ${ }^{\mathrm{b}}$ & $1.17[1.11-1.23]$ & $1.17[1.13-1.21]$ & $1.22[1.06-1.41]$ & $1.34[1.22-1.46]$ \\
\hline Low social support ${ }^{\mathrm{b}}$ & $1.27[1.20-1.33]$ & $1.02[0.99-1.06]$ & $1.19[1.06-1.34]$ & $1.03[0.95-1.11]$ \\
\hline Job strain $^{\mathrm{a}}$ & $1.29[1.21-1.37]$ & $1.18[1.13-1.23]$ & $1.30[1.17-1.45]$ & $1.00[0.93-1.08]$ \\
\hline Isostrain $^{\mathrm{a}}$ & $1.31[1.23-1.39]$ & $1.13[1.09-1.18]$ & $1.32[1.18-1.48]$ & $1.00[0.93-1.08]$ \\
\hline \multicolumn{5}{|l|}{ Quadrants by Karasek $^{\mathrm{a}}$} \\
\hline Active job (ref) & 1 & 1 & 1 & 1 \\
\hline Low strain & $1.08[1.02-1.15]$ & $1.31[1.26-1.36]$ & $0.71[0.58-0.87]$ & $1.01[0.90-1.13]$ \\
\hline Passive job & $1.39[1.31-1.47]$ & $1.42[1.36-1.47]$ & $1.08[0.93-1.25]$ & $1.55[1.41-1.70]$ \\
\hline High strain & $1.45[1.35-1.55]$ & $1.40[1.34-1.46]$ & $1.30[1.14-1.50]$ & $1.28[1.16-1.40]$ \\
\hline
\end{tabular}

${ }^{\mathrm{a}}$ Each exposure was studied separately

${ }^{\mathrm{b}}$ Demands, latitude and support were studied simultaneously

High strain (high demands and low latitude), low strain (low demands and high latitude), passive job (low demands and low latitude), and active job, the reference group (high demands and high latitude)

All models were adjusted for calendar time, biomechanical, physical, chemical and biological exposures 


\section{Author contributions}

IN is the principal investigator who designed the project and drafted and revised the manuscript. JFC and AM made substantial contributions to the design of the project. JFC, AM and AL were involved in revising the manuscript critically for important scientific content. JFC was in charge of all statistical analyses. BGP is in charge of the COSMOP dataset at Santé publique France and TC is in charge of the SUMER dataset at DARES; they both provided technical help on these datasets. All authors have read, reviewed and approved the final version of the manuscript. 


\section{Highlights}

- Psychosocial work factors were found to be associated with preventable mortality

- Strong associations were observed for alcohol-related mortality

- The fractions of preventable mortality attributable to these factors were significant among men 